\title{
Overview of methods used to evaluate the adequacy of nutrient intakes for individuals and populations
}

\author{
Blanca Román-Viñas ${ }^{1}$, Lluís Serra-Majem ${ }^{1,2} *$, Lourdes Ribas-Barba ${ }^{1}$, Joy $\mathrm{Ngo}^{1}$, \\ Alicia García-Álvarez ${ }^{1}$, Trudy M. A. Wijnhoven ${ }^{3}$, Garden Tabacchi ${ }^{4}$, Francesco Branca ${ }^{5}$, \\ Jeanne de Vries ${ }^{6}$ and Lisette C. P. G. M. de Groot ${ }^{6}$ \\ ${ }^{1}$ Community Nutrition Research Centre of the Nutrition Research Foundation, Barcelona Science Park, University of Barcelona, \\ C/Baldiri i Reixac, 4-6, 08028 Barcelona, Spain \\ ${ }^{2}$ University of Las Palmas de Gran Canaria, PO Box 550, 35080 Las Palmas de Gran Canaria, Spain \\ ${ }^{3}$ World Health Organization, Regional Office for Europe, Scherfigsvej 8, DK-2100 Copenhagen Ø, Denmark \\ ${ }^{4}$ Noncommunicable Diseases and Environment, Institute of Physiology and Human Nutrition, University of Palermo, Via Augusto \\ Elia 3, 90127 Palermo, Italy \\ ${ }^{5}$ Department of Nutrition for Health and Development, World Health Organization, Avenue Appia 20, CH-1211 Geneva 27, Switzerland \\ ${ }^{6}$ Division of Human Nutrition, Wageningen University and Research Centre, PO Box 8129, 6700EV Wageningen, The Netherlands
}

(Received 7 January 2009 - Revised 6 May 2009 - Accepted 1 June 2009)

\begin{abstract}
The objective of the present paper is to review the methods of measuring micronutrient intake adequacy for individuals and for populations in order to ascertain best practice. A systematic review was conducted to locate studies on the methodological aspects of measuring nutrient adequacy. The results showed that for individuals, qualitative methods (to find probability of adequacy) and quantitative methods (to find confidence of adequacy) have been proposed for micronutrients where there is enough data to set an average nutrient requirement (ANR). If micronutrients do not have ANR, an adequate intake (AI) is often defined and can be used to assess adequacy, provided the distribution of daily intake over a number of days is known. The probability of an individual's intake being excessive can also be compared with the upper level of safe intake and the confidence of this estimate determined in a similar way. At the population level, adequacy can be judged from the ANR using the probability approach or its short cut - the estimated average requirement cut-point method. If the micronutrient does not have an ANR, adequacy cannot be determined from the average intake and must be expressed differently. The upper level of safe intake can be used for populations in a similar way to that of individuals. All of the methodological studies reviewed were from the American continent and all used the methodology described in the Institute of Medicine publications. The present methodology should now be adapted for use in Europe.
\end{abstract}

Dietary intake: Adequacy: Micronutrients: Adequacy assessment: Adequacy measurement

The final stage in the dietary evaluation of an individual or a population is to compare the intake with the nutrient recommendations for that individual/population. Unfortunately, neither the true nutrient intake nor the nutrient requirements is known for every individual. Nutrient intake assessment is subject to uncertainties, such as the day-to-day variability of the intake, misreporting and method of evaluation. On the other hand, nutrient requirements are defined for certain age population groups, and an individual's requirement may differ from the ones defined for his/her population group. When assessing nutrient intake adequacy, the probability of adequacy is the only available option and the final decision about the adequacy of the diet will rely on several statements.
Recently, the European Community through the EURopean micronutrient RECommendations Aligned network has started working on the process of harmonising nutrient recommendations across Europe ${ }^{(1)}$. Such a process requires the investigation, analysis and discussion of each step needed to reach consensus on the definition of nutrient recommendations. In doing so, the difficulties in using recommendations for analysing nutrient intake adequacy will hopefully be reduced.

In North America, the first dietary standards published by the Canadian Council on Nutrition in 1938 and the Food and Nutrition Board in 1941 in the United States defined the Dietary Recommended Nutrient Intake (DRNI) and the RDA, respectively, as the nutritional requirement 'to serve

\footnotetext{
Abbreviations: ANR, average nutrient requirement; AI, adequate intake; DRI, dietary reference intake; EAR, estimated average requirement; INL 98 , individual nutrient level at 98 percentile; IOM, Institute of Medicine.

On behalf of EURRECA's RA.1.1 'Intake Methods' members: Serra-Majem L (Coordinator), Cavelaars A, Dhonukshe-Rutten R, Doreste JL, Frost-Andersen L, García-Álvarez A, Glibetic M, Gurinovic M, De Groot L, Henríquez-Sánchez P, Naska A, Ngo J, Novakovic R, Ortiz-Andrellucchi A, Øverby NC, Pijls L, Ranic M, Ribas-Barba L, Ristic-Medic D, Román-Viñas B, Ruprich J, Saavedra-Santana P, Sánchez-Villegas A, Tabacchi G, Tepsic J, Trichopoulou A, van 't Veer P, Vucic V,Wijnhoven TMA.

* Corresponding author: Lluís Serra-Majem, fax +3493 4034543, email lserra@dcc.ulpgc.es
} 
as a goal for good nutrition' for the population ${ }^{(2)}$. As such, the Dietary Recommended Nutrient Intake and RDA were used as nutrient standards to evaluate nutrient intake adequacy at population and individual levels. In North America/Canada, guidance for the evaluation of intakes has been developed after the most recent publication of Institute of Medicine (IOM)'s dietary standards ${ }^{(3)}$. This guidance includes new proposals about how to apply the proposed new references to nutritional assessment and counselling, and also which errors should be avoided when using such references.

In Europe, the first dietary standards were proposed in 1862 , for information as to how much food would be needed per person to prevent starvation ${ }^{(4)}$. From then on, as reported recently by Doets et al. ${ }^{(5)}$, considerable variability exists in nutrient recommendations across European countries, as most of them have developed and defined their own nutritional approaches to derive requirements (United Kingdom, German speaking countries, etc.) and have evaluated the nutritional status of their population and their compliance with recommendations. Advice on how to apply such recommendations has generally followed the guidelines elaborated in the IOM report.

In September 2007, the IOM gathered several scientific experts in a meeting in Washington DC to review the state of the art of definitions and applications, and new proposals for revising the dietary reference intake (DRI). One of the concerns and observations that arose in that meeting was the difficulty in applying the dietary references, the need for simpler guidance and the equivocal adherence of nutritionists and dietitians to the IOM committee recommendations for their applications $^{(6)}$.

Nutritional requirements are applied both to the nutritional assessment and to the planning of dietary interventions on an individual- and population-based level. Although the first DRI was published in 1940, little or no guidance was given about how to use them, until the IOM documents on applications were published in 2000, describing how requirements where derived and their application. Even then, not all researchers follow such advice, and they apply the nutritional requirements to assess nutritional intake adequacy in different ways. In the present supplement, Tabacchi et al. ${ }^{(7)}$ report that, after the year 2000, several population studies still use different cut-off point of the RDA (or individual nutrient level at 98 percentile (INL 98 )) as a reference for evaluating adequacy (163 out of 199 studies).

The purpose of the present review was to look for data on the presently proposed methods to evaluate adequacy of nutrient intake at the individual and population level.

\section{Material and methods}

For identification of the relevant literature, a specific search strategy was performed using explicit inclusion criteria. The search was carried out in database journal literature (MEDLINE and LILACS - Latin-American and Caribbean literature) and grey literature (Google), using the following keywords: 'nutrient inadequacy', 'nutrient inadequate intakes', 'nutrient adequacy', 'nutrient adequate intake', 'assessment', 'measurement', 'statistics', 'applications', 'methods', 'probability approach', 'estimated average requirement', 'Recommended dietary intake', 'upper intake limits', 'cutpoint approach', 'Dietary reference intake'. The medical subject headings term 'nutrition assessment' was also included.

The MEDLINE search was limited to human studies, but no limit of data or language was set. The Google search was limited to the first one-hundred citations. The search was finished in March 2008.

Titles and abstracts were evaluated for inclusion. Although at first only methodological studies were taken into consideration, population studies were also included for evaluation, as they contain information on different methodologies for measuring adequacy in the population under study.

The following exclusion criteria were applied for data selection: papers related to adjust the variability of intake, papers that evaluate individuals with any pathology, intervention studies, papers not having an abstract, assessment of nutrient intake adequacy based on food balance sheets, the applications of DRI for planning diets.

A manual review of the reference lists of the selected papers was done to identify additional papers for possible inclusion.

\section{Results}

The MEDLINE search on methodological papers measuring nutrient intake adequacy resulted in 1369 citations. After applying the exclusion criteria selection, a total of 167 papers were selected. Forty-four of them were methodological papers and 123 of them were population-based studies. The Google and LILACS search resulted in ten citations (eight papers and two books, one from the IOM and a supplement from ILSI Brazil).

All the methodological publications referred to the IOM publication and all but one were signed by researchers from the United States; only one was signed by a Brazilian author. Although the methodology to assess nutrient intake adequacy varies when referring to individuals or to populations, no publication was found dealing with the methodology to assess nutrient intake adequacy at individual level (except those explaining the procedure proposed by the IOM). Other methods to evaluate nutrient intake adequacy were found through the search into the methodology of the population studies found in the search, although no explanation was given about the scientific basis that supported such methods.

Only one study aimed to validate the methodology proposed by the IOM (the EAR cut-point method), by comparing the prevalence of inadequate intake using different methods, the cut-off point method, with cut-off points at the RDA (or INL $_{98}$ ), 0.66 RDA (INL 98 ), 0.50 RDA (INL 98 ) and the EAR (or average nutrient requirement (ANR)); the probability approach; and a Monte Carlo simulation. They concluded that using the $\mathrm{INL}_{98}, 0.66 \mathrm{INL}_{98}$ or $0.50 \mathrm{INL}_{98}$ as a cut-off limit induced an over- or underestimation of the real prevalence of inadequacy ${ }^{(8)}$.

The search for papers that evaluated nutrient intake adequacy obtained from original studies resulted in 123 publications, all of them were population-based surveys. The methods used in the studies were the following:

1. Scores of nutrient intake adequacy: The Nutrient Adequacy Ratio (NAR) and the Mean Adequacy Ratio (MAR) were the methods applied in five studies ${ }^{(9-13)}$, 
and certain diet indexes (Dietary Diversity Score and Food Variety Score) in one study ${ }^{(13)}$. The Nutrient Adequacy Ratio is an index of adequacy, which compares the individual's daily intake of a nutrient with the INL $_{98}$ for that nutrient. The Mean Adequacy Ratio calculates the average for the Nutrient Adequacy Ratio values for the selected nutrients for a certain individual ${ }^{(14)}$.

2. Two studies conducted in the United Kingdom calculated the proportion of the population whose intake were below the Lower Reference Nutrient Intake (LRNI) as a measure to assess nutrient intake adequacy ${ }^{(15,16)}$. In the United Kingdom, the Lower Reference Nutrient Intake is defined as the amount of a certain nutrient estimated to meet the needs of the lower $3 \%$ of the population. If individuals consume less than the lower reference nutrient intake, they will likely be deficient for such nutrient.

3. Percentage of individuals with nutrient intake values below $67 \%$ Adequate Intake (AI), at $100 \%$ estimated average intake; or below $67 \% \mathrm{RDA}^{(17)}$.

4. One Greek study compared the $95 \%$ CI of the intake with the INL98. If the DRI were contained within the CI, the authors concluded that there was no significant difference between the DRI and the observed nutrient intake ${ }^{(18)}$

5. Quartiles of AI: Those intakes at $25 \%$ of $\mathrm{AI}=0 \%$ probability of adequacy; nutrient intakes between 25 and $50 \%$ of the $\mathrm{AI}=25 \%$ probability of adequacy; nutrient intakes between 50 and $75 \%$ of the $\mathrm{AI}=50 \%$ probability of adequacy; nutrient intakes between 75 and $100 \%$ of the $\mathrm{AI}=75 \%$ probability of adequacy; and nutrient intakes at $100 \%$ of the $\mathrm{AI}=100 \%$ probability of adequacy ${ }^{(19)}$.

6. The $\mathrm{INL}_{98}$ for a nutrient (or some percentage of the INL $_{98}$ ) have been used as a cut-off value to assess the prevalence of nutrient inadequacy in numerous population studies. The proportions selected as cut-offs have varied, from two-thirds to one-third or a proportion such as $70 \%$, etc., with no clear criteria for the selection of the cited levels ${ }^{(17,20-43)}$.

7. The INL 98 has also been compared with the mean group intake, assuming that if that value approximates the INL 98 , only $2-3 \%$ of the group members would have inadequate intakes.

Most of the studies used the $\mathrm{INL}_{98}$ as a reference for measuring nutrient intake adequacy. The AI, or a cut point of the AI, was also used as a reference in some of the population studies.

\section{Discussion}

Because the nutrient requirements of every individual in a population are unknown, a true calculation of the prevalence of inadequacy is not possible, and statistical approaches are the only method to assess nutrient intake adequacy. As such, the only way to decide whether a method to assess nutrient intake adequacy is valid is to compare the method under study against other available methods to assess adequacy. From the present results, there was only one such study with the aim of validating a method to assess nutrient intake adequacy ${ }^{(8)}$. The authors validated the methodology proposed by the IOM (the EAR/ANR cut-point method) to assess nutrient intake adequacy at the population level. They concluded that the method gives a good estimation of the prevalence of inadequacy. They also concluded that when the EAR cut-point method does not work, a Monte Carlo simulation can be used ${ }^{(8)}$. The Monte Carlo simulation is an analytical method that randomly generates values to uncertain variables (a nutrient requirement for every individual in this case) with a probability distribution ${ }^{(8)}$.

Except for the IOM text, no attempt has been made to elucidate the use of statistical explanations or the procedure to follow for assessing the nutrient intake adequacy of a population, at least as a text that is accessible electronically. We are conscious that most of the literature regarding how to apply dietary recommendations is published in books, and generally not available by electronic means. This information was not reviewed and is a limitation of this analysis.

There was a lack of electronic publications for European data in the present review that could be used as a guide for application in Europe.

In principle, the methodology proposed by the IOM can be applied to assess the adequacy of nutrient intake in Europe, but some aspects of the procedure should be adapted to the specific characteristics of European intake data on nutrients. Following, there is a brief description of the issues to be resolved when applying the proposed methodology.

To begin with, the IOM procedure states that the methodology to be applied will depend upon the scope of the analysis (to assess nutrient intake adequacy at the individual or at the population level) and the nutrient under study, and therefore the ongoing recommendations for the given nutrient. As cited by Doets et al. ${ }^{(5)}$ in the context of the European micronutrient recommendations aligned network, there are great discrepancies in the nutritional recommendations across Europe, not only in terms of the actual nutrient value but also in the terminology used for defining requirements. The methodology to apply is different depending on whether EAR (or ANR) or AI data are available for a given nutrient. As such, in the case of $\mathrm{Ca}$, for example, some countries have defined an EAR (or ANR) and RDA (or INL98) value, while other countries apply only AI. To calculate the adequacy of $\mathrm{Ca}$ intake in the population, those countries utilising the EAR (or ANR) can apply the EAR cut-point method. Conversely, when AI is applied, intake adequacy can be determined only by qualitative methods.

Another obstacle to overcome is related to the fact that certain countries do not precisely define whether the value used in nutrient recommendations is an EAR (or ANR), reference nutrient intake (or RDA or $\mathrm{INL}_{98}$ ) or an AI. As a result, this makes it impossible to apply the first step of the recommended protocol.

Referring to an assessment at the individual level and following the protocol dictated by the IOM, in order to calculate the confidence that intake is adequate for a given person, it is necessary to know the variability of the requirement of the nutrient under study and the variability of its intake in the population. The variability of the requirement is set when the nutrient requirement distribution is defined. The IOM text specifies that a $10-15 \%$ coefficient of variability is set when there is insufficient data about the nutrient's distribution. In European countries, when such a coefficient is unknown, should we also assume the same percentage range 
of variability? Should European countries use another value or is the IOM recommendation appropriate for European citizens as well? To calculate nutrient intake adequacy at the individual level, knowledge of variability of the given nutrient's intake in the population is also needed. In the United States and Canada, data from the Continuing Survey of Food Intake of Individuals (CSFII) is used as a reference to obtain such values. In Europe, at the moment, there is no consensus on what food consumption database should be used to obtain this kind of information. Should every country use its own data, in the case that it is available? If availability is an issue, a single database should be the reference tool to be applied throughout Europe. In the present context, the initiative of the European Food Safety Authority to develop the Concise European Food Consumption database for the adult population for use as a screening tool in exposure assessment (www.efsa.europa.eu) could be an initial step in the development of a common European nutrient consumption database. Also, other datasets such as EPIC or Efcoval could be of use.

When referring to nutrient intake assessment at the population level, the present results showed that most of the methodologies used in population studies to assess nutrient intake adequacy were not totally appropriate, a conclusion that has also been pointed out by Jahns et al. ${ }^{(44)}$ in reference to studies conducted in the United States. In the present search, numerous population studies conducted from 2000 onwards (when the IOM text was published) still used a cut-off point of the INL $_{98}$ or a comparison of the mean intake with the $\mathrm{INL}_{98}$ as a reference for evaluating adequacy. Comparing the mean intake of a group of individuals with the $\mathrm{INL}_{98}$ will underestimate the prevalence of individuals at the risk of inadequate intake. Such conclusions have been explained both by the IOM report ${ }^{(6)}$ on nutritional assessment and by Beaton ${ }^{(45)}$ and Anderson ${ }^{(46)}$. The INL $_{98}$ for a nutrient takes into account the individual variability of the requirement and thus exceeds the requirement of almost all individuals.

When using a cut point of the INL 98 as a measure of inadequacy, the prevalence of inadequacy should be corrected by taking the sensitivity and specificity of the cut-off point into account. Otherwise, this approach will lead to conservative estimates of the prevalence of inadequacy ${ }^{(47)}$. As Lauzon ${ }^{(8)}$ described, by using the INL $_{98}, 0.66$ INL $_{98}$ or 0.50 INL $_{98}$ as a cut-off limit, an over- or underestimation of the real prevalence of inadequacy must be assumed.

Once a decision has been made on how to proceed with the obstacles described earlier and in order to correctly apply the procedure of the IOM, the design of studies where nutrient intake adequacy is to be assessed should follow certain methodological aspects:

1. The size of the sample under study has to be large enough. If the study population is too small, the application of the statistical methods for adjusting the day-to-day variation of intake may not be possible. It is recommended not to use the probability approach method to assess groups of less than 100 individuals $^{(48)}$.

2. Intake distributions should be adjusted to remove the effect of day-to-day variation so as to apply the probability approach or the EAR cut point, and to assess the risk of excessive intake. Otherwise, the evaluation of nutrient intake adequacy will be over- or underestimated. A publication about how the methods to adjust for the variability of intake affect the nutrient intake adequacy assessment has been published in the present supplement $^{(49)}$. For those nutrients with an AI, the mean intake of a group can be compared with the AI. In this case, the intake distribution does not need to be adjusted for day-to-day variation, as only the mean intake is being examined ${ }^{(50)}$.

3. As stated by Poslusna et al. ${ }^{(51)}$ in the present supplement, it is debatable as to whether underreporters should be excluded from data analysis or whether their intake data should be corrected for inclusion in the analysis. One school of thought is that to assess nutrient intake adequacy, it is necessary to detect underreporters to reduce the bias in estimating the prevalence of inadequacy. Lauzon et al. ${ }^{(8)}$ estimated that the inclusion of underreporters in the evaluation of the prevalence of nutrient inadequacy could increase up to $17 \%$ points in classifying individuals as having inadequate intakes. Also Becker \& Welten ${ }^{(52)}$ estimated the effect that underreporters had in the assessment of meeting recommendations for certain vitamins with data from a Swedish survey. The authors showed that the proportion of individuals with vitamin intakes below the average requirement decreased when those individuals reporting questionably low energy intakes were excluded.

4. To correctly evaluate the risk of excessive intake for a certain nutrient, all sources of the nutrient (supplements, fortification, medication, etc.) need to be assessed and included in data analysis.

If these four conditions are not met, the assessment of nutrient intake adequacy will neither be appropriate nor valid to serve as the basis for making decisions or taking actions to improve nutritional habits of the population under study.

\section{Conclusions}

From the literature reviewed, the IOM text is the main reference used to assess nutrient intake adequacy. To correctly apply the recommended methodologies, it is urgent to reach a consensus about how European countries should proceed when assessing nutrient intake adequacy in nutritional surveys.

\section{Acknowledgements}

The studies reported herein have been carried out within the EURopean micronutrient RECommendations Aligned network of excellence (www.eurreca.org), financially supported by the Commission of the European Communities, specific Research, Technology and Development (RTD) Programme Quality of Life and Management of Living Resources, within the Sixth Framework Programme, contract no. 036196. The present report does not necessarily reflect the Commission's views or its future policy in this area. Additional support from 
Margaret Ashwell and Dr. Janet Lambert in reviewing concepts and contents is gratefully acknowledged. B. R.-V. screened the literature, undertook analysis and wrote the first draft of the paper. L. S.-M. was the supervisor of the study and revised the paper providing expert advice on data interpretation and discussion of the paper. L. R.-B. contributed to the literature search strategy, screened part of the literature and supervised the final draft of the paper. J. N. commented on drafts of the paper. A. G.-A. contributed to the design of the review and commented on the drafts of the paper. T. M. A. W. revised the paper providing expert advice on data interpretation. G. T. contributed to the literature search strategy and commented on drafts of the paper. F. B. commented on the drafts of the paper. J. d. V. commented on the drafts of the paper. L. C. P. G. M. d. G. commented on the drafts of the paper. The authors have no conflict of interests to report.

\section{References}

1. Ashwell M, Lambert JP, Alles MS, et al. (2008) How we will produce the evidence-based EURRECA toolkit to support nutrition and food policy. Eur J Nutr 47, Suppl. 1, 2-16.

2. National Research Council (1941) Recommended Dietary Allowances. Washington, DC: National Research Council.

3. Institute of Medicine (2000) Dietary Reference Intakes: Applications in Dietary Assessment. Washington, DC: National Academy Press.

4. Leitch I (1942) The evolution of dietary standards. Nutr Abs Rev 11, 509-521.

5. Doets EL, de Wit LS, Dhonukshe-Rutten RA, et al. (2008) Current micronutrient recommendations in Europe: towards understanding their differences and similarities. Eur J Nutr 47, Suppl. 1, 17-40.

6. Institute of Medicine (2008) The Development of DRIs 1994-2004: Lessons Learned and New Challenges Workshop Summary. Washington, DC: The National Academies Press.

7. Tabacchi G, Wijnhoven TMA, Branca F, et al. (2009) How is the adequacy of micronutrient intake assessed across Europe? A systematic literature review. Br J Nutr 101, Suppl. 2, S29-S36.

8. Lauzon B, Volatier JL \& Martin A (2004) A Monte Carlo simulation to validate the EAR cut-point method for assessing the prevalence of nutrient inadequacy at the population level. Public Health Nutr 7, 893-900.

9. Johnson RK, Smiciklas-Wright $\mathrm{H}$, Crouter AC, et al. (1992) Maternal employment and the quality of young children's diets: empirical evidence based on the 1987-1988 Nationwide Food Consumption Survey. Pediatrics 90, 2 Pt 1, 245-249.

10. Lopes ACS (2005) Nutrient consumption by adults and seniors in a population-based study: the Bambuí Project. Cad. Saúde Pública 21, 1201-1209.

11. Guendelman S \& Abrams B (1995) Dietary intake among Mexican-American women: generational differences and a comparison with white non-Hispanic women. Am J Public Health 85, 20-25.

12. Sudo N \& Ohtsuka R (2001) Nutrient intake among female shift workers in a computer factory in Japan. Int J Food Sci Nutr 52, $367-378$.

13. Torheim LE, Ouattara F, Diarra MM, et al. (2004) Nutrient adequacy and dietary diversity in rural Mali: association and determinants. Eur J Clin Nutr 58, 594-604.
14. Gibson RS (1993) Nutritional Assessment. A Laboratory Manual. New York: Oxford University Press.

15. McNulty H, Eaton-Evans J, Cran G, et al. (1996) Nutrient intakes and impact of fortified breakfast cereals in schoolchildren. Arch Dis Child 75, 474-481.

16. Eves A \& Gesch B (2003) Food provision and the nutritional implications of food choices made by young adult males, in a young offenders' institution. J Hum Nutr Diet 16, 167-179.

17. Marshall TA, Stumbo PJ, Warren JJ, et al. (2001) Inadequate nutrient intakes are common and are associated with low diet variety in rural, community-dwelling elderly. J Nutr 131, 2192-2196.

18. Petrakos G, Panagopoulos P, Koutras I, et al. (2006) A comparison of the dietary and total intake of micronutrients in a group of pregnant Greek women with the dietary reference intakes. Eur J Obstet Gynecol Reprod Biol 127, 166-171, Epublication 9 November 2005.

19. Murphy SP \& Vorster HH (2007) Methods for using nutrient intake values (NIVs) to assess or plan nutrient intakes. Food Nutr Bull 1 Suppl., S51-S60.

20. Harrill I \& Cervone N (1977) Vitamin status of older women. Am J Clin Nutr 30, 431-440.

21. Groenewald G, Langenhoven ML, Beyers MJ, et al. (1981) Nutrient intakes among rural Transkeians at risk for oesophageal cancer. S Afr Med J 60, 964-967.

22. Koh ET (1984) Comparison of dietary energy intakes and sources by race, sex, and age for adults in Mississippi. $J$ Am Diet Assoc 84, 788-794.

23. Bourne LT, Langenhoven ML, Steyn K, et al. (1994) Nutritional status of 3-6 year-old African children in the Cape Peninsula. East Afr Med J 71, 695-702.

24. Zive MM, Taras HL, Broyles SL, et al. (1995) Vitamin and mineral intakes of Anglo-American and Mexican-American preschoolers. J Am Diet Assoc 95, 329-335.

25. Zive MM, Nicklas TA, Busch EC, et al. (1996) Marginal vitamin and mineral intakes of young adults: the Bogalusa Heart Study. J Adolesc Health 19, 39-47.

26. Peterson S \& Sigman-Grant M (1997) Impact of adopting lower-fat food choices on nutrient intake of American children. Pediatrics 100, E4.

27. Vaughan LA, Benyshek DC \& Martin JF (1997) Food acquisition habits, nutrient intakes, and anthropometric data of Havasupai adults. J Am Diet Assoc 97, 1275-1282.

28. Nicklas TA, Myers L, Reger C, et al. (1998) Impact of breakfast consumption on nutritional adequacy of the diets of young adults in Bogalusa, Louisiana: ethnic and gender contrasts. $J$ Am Diet Assoc 98, 1432-1438.

29. Rose D, Habicht JP \& Devaney B (1998) Household participation in the Food Stamp and WIC programs increases the nutrient intakes of preschool children. J Nutr 128, $548-555$.

30. Briefel RR, Bialostosky K, Kennedy-Stephenson J, et al. (2000) Zinc intake of the U.S. population: findings from the third National Health and Nutrition Examination Survey, 1988-1994. J Nutr 130, 5S Suppl., 1367S-1373S.

31. Nicklas TA, Reger C, Myers L, et al. (2000) Breakfast consumption with and without vitamin-mineral supplement use favorably impacts daily nutrient intake of ninth-grade students. J Adolesc Health 27, 314-321.

32. Serra Majem L, Ribas Barba L, Armas Navarro A, et al. (2000) Energy and nutrient intake and risk of inadequate intakes in Canary Islands (1997-98). Arch Latinoam Nutr 50, 1 Suppl. 1, 7-22.

33. Stang J, Story MT, Harnack L, et al. (2000) Relationships between vitamin and mineral supplement use, dietary intake, and dietary adequacy among adolescents. J Am Diet Assoc 100, 905-910. 
34. Aranceta J, Serra-Majem L, Pérez-Rodrigo C, et al. (2001) Vitamins in Spanish food patterns: the eVe Study. Public Health Nutr 4, 1317-1323.

35. Wierzbicka E, Brzozowska A \& Roszkowski W (2001) Energy and nutrients intake of elderly people living in the Warsaw region, Poland. J Nutr Health Aging 5, 248-252.

36. Charlton KE, Bourne LT, Steyn K, et al. (2001) Poor nutritional status in older black South Africans. Asia Pac J Clin Nutr 10, 31-38.

37. Serra Majem L, Ribas L, Pérez-Rodrigo C, et al. (2002) Determinants of nutrient intake among children and adolescents: results from the enKid Study. Ann Nutr Metab 46, Suppl. 1, $31-38$.

38. Sharkey JR, Branch LG, Zohoori N, et al. (2002) Inadequate nutrient intakes among homebound elderly and their correlation with individual characteristics and health-related factors. Am J Clin Nutr 76, 1435-1445.

39. Corrêa Leite ML, Nicolosi A, Cristina S, et al. (2003) Dietary and nutritional patterns in an elderly rural population in Northern and Southern Italy: (II). Nutritional profiles associated with food behaviours. Eur J Clin Nutr 57, 1522-1529.

40. Peña E, Sánchez A, Portillo Z, et al. (2003) Dietary evaluation of pregnant adolescents during first, second and third trimester. Arch Latinoam Nutr 53, 133-140.

41. Serra Majem L, Ribas L, García A, et al. (2003) Nutrient adequacy and Mediterranean diet in Spanish school children and adolescents. Eur J Clin Nutr 57, Suppl. 1, S35-S39.

42. Tur JA, Serra-Majem L, Romaguera D, et al. (2004) Does the diet of the Balearic population, a Mediterranean type diet, still provide adequate antioxidant nutrient intakes? Eur J Nutr 44, 204-213.
43. Monge-Rojas R, Barrantes M, Holst I, et al. (2005) Biochemical indicators of nutritional status and dietary intake in Costa Rican Cabécar Indian adolescents. Food Nutr Bull 26, 3-16.

44. Jahns L, Arab L \& Carriquiry A (2003) Dietary reference intakes still used incorrectly in journal articles. $J$ Am Diet Assoc 103, 1292-1293.

45. Beaton GH (1985) Uses and limits of the use of the recommended dietary allowances for evaluating dietary intake data. Am J Clin Nutr, 155-164.

46. Anderson GH (1982) Estimating nutrient deficiencies in a population from dietary records: the use of probability analyses. Nutr Res 2, 409-415.

47. Carriquiry AL (1999) Assessing the prevalence of nutrient inadequacy. Pub Health Nutr 2, 23-33.

48. Murphy SP, Guenther PM \& Kretsch MJ (2006) Using the dietary reference intakes to assess intakes of groups: pitfalls to avoid. $J$ Am Diet Assoc 106, 1550-1553.

49. Ribas-Barba L, Serra-Majem L, Román-Viñas B, et al. (2009) Effects of dietary assessment methods on assessing risk of nutrient intake adequacy at the population level: from theory to practice. Br J Nutr 101, Suppl. 2, S64-S72.

50. Murphy SP \& Vorster HH (2007) Methods for using nutrient intake values (NIVs) to assess or plan nutrient intakes. Food Nutr Bull 28, Suppl. 1, S51-S60.

51. Poslusna K, Ruprich J, Vries J, et al. (2009) Misreporting of energy and micronutrient intake estimated by food records and 24 hour recalls, control and adjustment methods in practice. Br J Nutr 101, Suppl. 2, S73-S85.

52. Becker W \& Welten D (2001) Under-reporting in dietary surveys - implications for development of food-based dietary guidelines. Public Health Nutr 4, 683-687. 